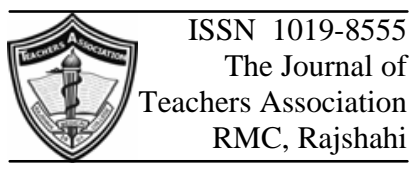

\title{
Editorial
}

\section{Endoscopic Evaluation of Achalasia Cardia}

\author{
Md. Abdul Ahad*
}

The evaluation of esophageal motility disorders often begins with endoscopy. Many diagnoses can be made with endoscopy alone, although some require manometry or barium x-ray study for confirmation. Achalasia cardia is a condition where endoscopic evaluation is becoming popular.

Achalasia is an uncommon disorder that involves loss of neurons or ganglion cells in the myenteric plexus of the lower esophageal sphincter (LES) and the body of the esophagus. These neurons allow relaxation of the LES through inhibition of the normally contracted LES smooth muscle, and their loss can lead to the failure of the LES to relax with swallowing. Symptoms of achalasia include dysphagia to solids and liquids, regurgitation chest pain, and weight loss. ${ }^{1,2}$

Diagnosis of achalasia lies in findings on manometry, barium esophagram, and endoscopy. Many of these findings are similar whether the disease is primary or secondary, for instance due to Chagas' disease or malignancy at the gastroesophageal junction (GEJ). Manometry is the most important diagnostic test. It typically shows absent or incomplete relaxation of the LES with wet swallows and aperistalsis (no smooth muscle contractions or simultaneous contractions of the body of the esophagus after wet swallows). A higher LES resting pressure is also often seen. Barium swallow typically shows a dilated esophagus with a "bird's beak" narrowing distally due to the contracted LES. Late in the disorder, the esophagus is severely dilated and takes on the contortions of a "sigmoid" shape. This results from longstanding aperistalsis and the lack of LES relaxation.

In patients with suspected achalasia, endoscopy is performed to exclude pseudoachalasia, that is, GEJ tumors that can mimic primary achalasia. In patients not known to have achalasia, for instance in a patient undergoing esophagogastroduodenoscopy (EGD) to evaluate regurgitation or chest pain, the diagnosis can be suggested by a constellation of findings, including a feeling of resistance at the LES that suddenly gives way, with the endoscope "popping" into the stomach, due to the contracted LES smooth muscle. The spectrum of endoscopic findings worsens as the disease progresses, from a normal-appearing esophagus ${ }^{1,2}$ to a dilated and tortuous "sigmoid" esophagus. There is often retained fluid or food and a longer period of fasting prior to endoscopy may be needed. The mucosa of the esophagus often appears normal, but stasis of fluid, food, or pills may cause friability, erosions, or Candida esophagitis.

Cameron et al. ${ }^{3}$ used videoendoscopy to evaluate achalasia. A standard endoscope was passed to 25 $\mathrm{cm}$, and then to just proximal to the LES. The patients were videotaped during swallowing. Lumen-occluding peristaltic contractions were seen in only 1 of 20 patients with achalasia. This absence of peristalsis was also seen in patients

*Assistant Professor, Department of Gastroenterology, Rajshahi Medical College, Rajshahi. 
with scleroderma. The LES can appear puckered and may not open with air insufflation. ${ }^{3}$ However, with gentle pressure, the endoscope should pass easily. If more pressure is needed to cross the GEJ, pseudoachalasia due to a malignancy should be suspected. ${ }^{4}$

Endoscopy plays a crucial role in ruling out mechanical stricture and malignancy. However, despite a careful evaluation of the distal esophagus and cardia, a tumor can be missed in more than one third of patients because of submucosal growth. ${ }^{4} 5$ Biopsies, although important, can also be negative because of the infiltrative nature of some of these tumors. If a malignancy is suspected, patients should undergo testing with computed tomography scan or endoscopic ultrasound (EUS). Even with additional testing, some tumors remain elusive., ${ }^{4}$ Endoscopic ultrasound may be helpful in evaluating for malignancy by showing esophageal wall thickness and disruption of the normal wall architecture. However, a thickened wall can be seen near the GEJ in patients with primary achalasia. ${ }^{7,8} 9$ Some of this may be due to a tangential imaging artifact in patients with a tortuous esophagus. ${ }^{10,11}$

Though not the sole diagnostic tool, endoscopy is used in conjunction with esophageal manometry and barium $\mathrm{x}$-rays to evaluate patients with esophageal motility disorders. Endoscopic findings are less helpful in scleroderma and the spastic disorders of nutcracker esophagus and diffuse esophageal spasm, as the findings are often normal with these entities. Endoscopy is helpful in diagnosing diverticula and ringed esophagus. It is mandatory in achalasia to aid exclusion of malignancy.

\section{References}

1. Howard PJ, Maher L, Pryde A, Cameron EW, Heading RC. Five year prospective study of the incidence, clinical features, and diagnosis of achalasia in Edinburgh. Gut 1992;33:1011-1015.

2. Ho KY, Tay HH, Kang JY. A prospective study of the clinical features, manometric findings, incidence and prevalence of achalasia in Singapore. $J$ Gastroenterol Hepatol 1999; 14:791-795.

3. Cameron AJ, Malcolm A, Prather CM, Phillips SF. Videoendoscopic diagnosis of esophageal motility disorders. Gastrointest Endosc 1999;49:62-69.

4. Tracey JP, Traube M. Difficulties in the diagnosis of pseudoachalasia. Am J Gastroenterol 1994; 89: 2014-2018.

5. Rozman RWJr, Achkar E. Features distinguishing secondary achalasia from primary achalasia. Am J Gastroenterol 1990; 85:1327-1330.

6. Ziegler K, Sanft C, Friedrich M, Gregor M, Riecken EO. Endosonographic appearance of the esophagus in achalasia. Endoscopy 1990; 22:1-4.

7. Hatlebakk JG, Odegaard S. Endoscopic ultrasound: a new look at achalasia? Eur J Gastroenterol Hepatol 1998; 10:543-545.

8. Barthet $\mathrm{M}$, Mambrini $\mathrm{P}$, Audibert $\mathrm{P}$, et al. Relationships between endosonographic appearance and clinical or manometric features in patients with achalasia. Eur J Gastroenterol Hepatol 1998; 10:559-564.

9. $\mathrm{Xu} G M$, Niu YL, Zou XP, Jin ZD, Li ZS. The diagnostic value of transendoscopic miniature ultrasonic probe for esophageal diseases. Endoscopy 1998; 30(suppl 1): A28-A32.

10. Van Dam J, Falk GW, Sivak MVJr, Achkar E, Rice TW. Endosonographic evaluation of the patient with achalasia: appearance of the esophagus using the echoendoscope. Endoscopy 1995;27:185-190.

11. Van Dam J. Endosonographic evaluation of the patient with achalasia. Endoscopy 1998; 30(suppl 1): A48-A50. 